Check for updates

Cite this: Mater. Adv., 2022, 3,2884

Received 2nd January 2022,

Accepted 11th February 2022

DOI: $10.1039 / \mathrm{d} 2 \mathrm{ma} 00004 \mathrm{k}$

rsc.li/materials-advances

\title{
Honeycomb-structured copper indium sulfide thin films obtained via a nanosphere colloidal lithography method $\dagger$
}

\author{
Efthymia Vakalopoulou, (D) a Thomas Rath, (D) *a \\ Fernando Gustavo Warchomicka, (D) ${ }^{b}$ Francesco Carraro, (D) ${ }^{c}$ Paolo Falcaro, (D) ${ }^{c}$ \\ Heinz Amenitsch (D) ${ }^{d}$ and Gregor Trimmel (D) ${ }^{a}$
}

\begin{abstract}
The large surface-to-volume ratio and the huge surface area of an ordered nanostructure is essential for improving the performance of many metal sulfide-based technologies within energy conversion and storage, but also catalysis and sensing. Although, several routes toward the formation of nanostructured metal sulfide thin films have been already developed, their fabrication is still challenging. Herein, we present a novel method for the preparation of honeycomb-structured CulnS $_{2}$ thin films via a nanosphere colloidal lithography technique using monodisperse polystyrene nanosphere layers, formed by a self-assembly approach at the air/liquid interface, as template. The size of the spheres can be reduced by an $\mathrm{O}_{2}$ plasma etching process, thereby enlarging the free space between the spheres. Infiltration of the template with metal xanthates followed by their thermal conversion to $\mathrm{CulnS}_{2}$ and the thermal removal of the polymeric template leads to ordered honeycomb-structured films. In an alternative route, the template is infiltrated with a tailored CulnS $_{2}$ nanoparticle ink before the template is removed by dissolution.
\end{abstract}

\section{Introduction}

In the past few years, ordered nanostructured materials gained increasing interest in optoelectronics, sensors, but also in energy related applications including batteries, capacitors, solar cells and in particular catalytic $\mathrm{CO}_{2}$ reduction, or hydrogen production. ${ }^{1,2}$ For the formation of ordered nanostructured materials, metal oxides, siliceous and carbon based materials are prevalent among the research community. The reason for this pre-eminence is mainly the huge amount of suitable precursors and their ability to take part in sol-gel reactions. ${ }^{3}$ In contrast, due to their less controlled sol-gel processes and sensitivity towards experimental conditions, reports about

\footnotetext{
${ }^{a}$ Institute for Chemistry and Technology of Materials, NAWI Graz, Graz University of Technology, Stremayrgasse 9, 8010 Graz, Austria. E-mail: thomas.rath@tugraz.at

${ }^{b}$ Institute of Materials Science, Joining and Forming, Graz University of Technology, Kopernikusgasse 24, 8010, Graz, Austria

${ }^{c}$ Institute of Physical and Theoretical Chemistry, NAWI Graz, Graz University of Technology, Stremayrgasse 9, 8010 Graz, Austria

${ }^{d}$ Institute of Inorganic Chemistry, NAWI Graz, Graz University of Technology, Stremayrgasse 9, $8010 \mathrm{Graz}$, Austria

$\dagger$ Electronic supplementary information (ESI) available: Additional SEM images, SEM-EDX, GIWAXS and GISAXS data, FT-IR and UV-vis spectra. See DOI: 10.1039/ d2ma00004k
}

routes towards ordered nanostructured films of sulfides, selenides, carbides and nitrides are scarce. ${ }^{3}$ Especially metal sulfides, widely used in applications such as energy conversion and storage, catalysis and water splitting, ${ }^{4,5}$ can benefit from the formation of ordered nanostructures as the large surface-tovolume ratio of the structured materials can be a key point for further improving their performance in these above mentioned applications. $^{6}$

The major structuring techniques are based on templates. There are two templating strategies, namely hard-templating or nanocasting routes, and soft-templating. The first route employs usually a hard exotemplate, such as mesoporous silica, ${ }^{7}$ whereas the second uses structure directing agents, such as liquid crystals. ${ }^{8}$ Both techniques face several limitations. In the case of the soft-templating route, in contrast to the metal oxides, which can be easily formed via oxidation of metal-based compounds at elevated temperatures under ambient atmosphere, the metal sulfide formation requires, in most of the cases, two precursor materials: one that provides the metal ion and the other providing the sulfur ion. However, the coexistence of the two precursors and their high reactivity, immediately leads to the metal sulfide precipitation and uncontrolled growth. As a result, the precursors do not have the time to interact with the structure directing agent. Additionally, the experimental conditions, such as temperature and $\mathrm{pH}$ values, 
which are needed for the self-assembly of the soft-template are typically different to the ones needed for the crystallization of the metal sulfide. ${ }^{9,10}$ In case of the nanocasting route, even though the exotemplate is not influenced by the conditions needed for the formation of the metal sulfides, as they are produced at an earlier step and it can be stable at very high temperatures, the main problem lies on the use of hazardous chemicals (e.g. HF) for its removal. ${ }^{7}$ Lastly, a general challenge regarding the preparation of structured metal sulfide layers is due to the used precursor materials (e.g. metal salts and a sulfur source, or single source precursors) and their shrinkage in volume during the conversion, which can be up to $90 \% .^{10,11}$ This issue leads to the need of numerous repetitions of the infiltration and conversion steps until the desired result is obtained or a loss of the interconnected porous structure causing a decrease of the accessible surface area.

Apart from the templating route, other techniques were introduced for the formation of ordered nanostructured metal sulfide thin films, such as UV-light lithography, which is performed with the aid of metal xanthate precursors acting as negative resist. ${ }^{12}$ Metal xanthates are metal organic compounds with a typical metal-sulfur bond, which can decompose at elevated temperatures or in certain conditions also at room temperature resulting into metal sulfides and are therefore considered as single-source precursors. ${ }^{13,14}$ An alternative to UV lithography is the e-beam lithography, where suitable single source precursors, such as metal thiolates or xanthates, as well as long-chain metal anion-alkyl ammonium complexes ${ }^{15}$ are lithographically patterned for the formation of structured metal sulfides. Both UV and e-beam lithography techniques do not use all the typical steps of a conventional lithography, but only the exposure, which converts the soluble precursor to the insoluble metal sulfide and subsequently the development, which removes the precursor via a dissolution in a common solvent, such as chloroform. These lithographic techniques have the disadvantages of low throughput, high costs and time-consuming preparation of the templates.

Another method for the formation of patterned metal sulfide microarrays is via self-assembled monolayers (SAMs) as functional organic templates. ${ }^{16}$ SAMs are patterned usually via UV-lithography, which results in the formation of different functionalities and subsequently can induce the adsorption and crystallization of the metal sulfides only in desired positions. A less known technique is the micromolding in capillaries (MIMIC). ${ }^{17}$ The technique employs an elastomeric stamp which is placed on the substrate. A small amount of the precursor solution is positioned at the end of the stamp and due to capillary forces, the micromold is filled. Drying and posttreatment steps follow, resulting into patterned structures. Nevertheless, the complex fabrication protocol makes the latter techniques cumbersome structuring routes.

An alternative method overcoming several of the aforementioned limitations is the nanosphere colloidal lithography. ${ }^{18}$ This type of lithography, also referred to as natural lithography, ${ }^{19}$ is a patterning method, where colloidal monodispersed particles are self-assembled and used as a template for the production of periodically ordered arrays. Compared to the common lithography techniques, nanosphere colloidal lithography is also highly reproducible and controllable, however, as no special equipment is necessary, it is simpler and less expensive. Additionally, the structure size can range from tens of nanometers up to several micrometers. At the moment, popular colloidal particles are silica and polymer spheres, such as polystyrene (PS) and poly(methyl methacrylate) (PMMA). ${ }^{20}$ The spheres are assembled into hexagonally structured arrays via several methods, such as drop-, dip- and spin-coating, electrophoretic deposition and self-assembly at the gas/liquid interface. ${ }^{21}$ Hence, the hexagonally structured spheres can be used as templates, known also as opal, where the desired materials are infiltrated in the interstitial space of the spheres. Subsequently, the template is removed, resulting into the negative architecture of the material, also known as inverse opal (IO). In the literature, there are numerous studies that employ the nanosphere colloidal lithography to form hexagonally structured thin films. However, these reports focus on the syntheses of inorganic materials, such as the oxides $\mathrm{TiO}_{2},{ }^{22,23}$ $\mathrm{SiO}_{2},{ }^{23,24} \mathrm{In}_{2} \mathrm{O}_{3},{ }^{25}$ ITO $^{26}$ and organometal halide perovskites, ${ }^{27}$ as well as $\mathrm{Ag},{ }^{28} \mathrm{Ni}-\mathrm{P} .{ }^{29}$

In this study, we present the preparation of honeycombstructured $\mathrm{CuInS}_{2}$ thin films via two colloidal nanosphere lithography approaches. $\mathrm{CuInS}_{2}$ is a well-studied, non-toxic, ternary metal sulfide material ${ }^{30}$ and macroporous structured $\mathrm{CuInS}_{2}$ films are of high interest in applications such as (photo)catalysis for water splitting ${ }^{5}$ and inorganic-organic heterojunction solar cells., ${ }^{2,34}$ Regarding the solution-based formation of $\mathrm{CuInS}_{2}$ thin films, there are several studies focusing on either salts precursors ${ }^{31}$ or metal xanthates. ${ }^{32,33}$ Here, in the first investigated colloidal lithography route, a direct infiltration of a precursor solution containing copper and indium xanthates and an in situ thermal conversion to the metal sulfide is applied. In the second route, novel thioglycerol-capped $\mathrm{CuInS}_{2}$ nanocrystals (NCs) were synthesised, characterized and employed for the formation of honeycomb-structured thin films.

\section{Results and discussion}

\section{a. Formation and characterization of the PS-NS templates}

The polystyrene nanosphere (PS-NS) templates were prepared with an air/liquid interface method using a suspension of the PS-NS in a water/ethanol mixture. The overall preparation process is illustrated in Fig. 1. A glass slide is placed in the centre of a Petri dish, an amount of the suspension is dropped on the glass slide and subsequently water is slowly added until the PS suspension is rapidly spread on the air/water interface, leading to the two-dimensional (2D) layer assembly. Upon the formation of the layer, a blueish structural colour appeared at the air/liquid interface, generated when the incident light on the ordered structure undergoes diffraction and the wavelength of the reflected light fulfils the Bragg's conditions. ${ }^{35}$ Subsequently, the transfer of the PS-NS arrays on the substrates (silicon wafer) was performed by inserting the substrates below 


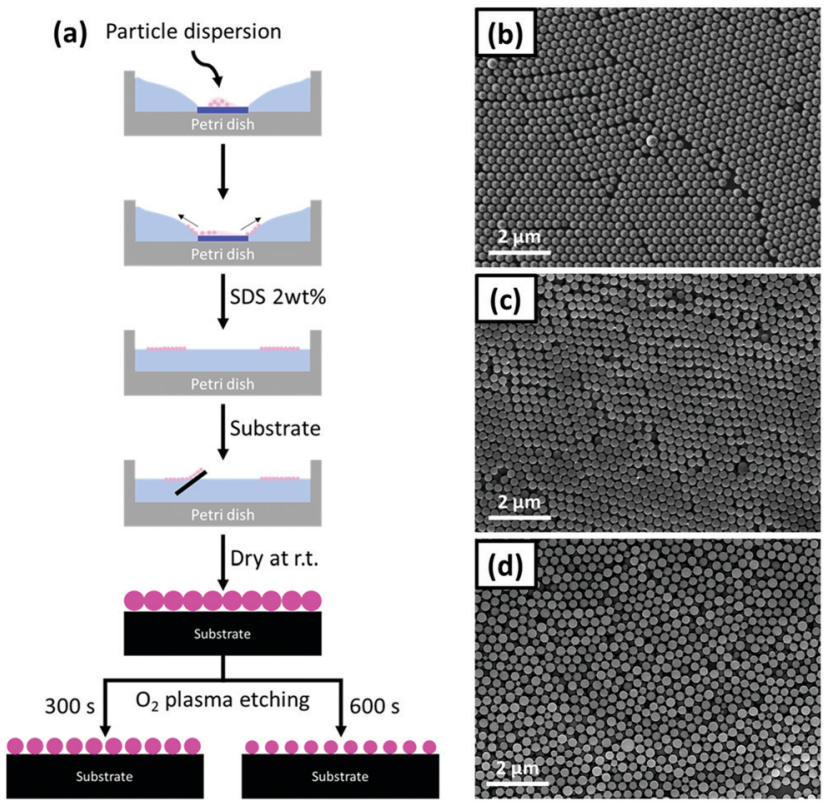

Fig. 1 (a) Schematic illustration of the overall preparation process of the PS-NS templates. SEM images of (b) P0, (c) P300 and (d) P600 PS-NS templates.

the layer and lifting them from the interface. Finally, the PS-NS templates immobilized on the substrates were dried under ambient conditions. In Fig. 1(b) and Fig. S1 (ESI $\dagger$ ), the SEM images of the closely-packed PS-NS arrays on the substrate are depicted, with the sphere diameter being $264 \pm 20 \mathrm{~nm}$.

However, the 2D hexagonal packing of the nanospheres was so tight that the interstitial space was insufficient for the formation of stable walls made of the infiltrated material. Thus, the PS-NS templates were modified by $\mathrm{O}_{2}$ plasma etching. This leads to a size reduction of the spheres and consequently to an interstitial space increase between the spheres. The $\mathrm{O}_{2}$ plasma etching is an isotropic process, meaning that it is performed not only on the surface but also into existing cavities. ${ }^{36}$ As a result, the size of the spheres was homogeneously reduced depending on the etching durations. In our work, we operated an $\mathrm{O}_{2}$ plasma etching for 300 and $600 \mathrm{~s}$. The diameter after $300 \mathrm{~s}$ was at approx. $236 \mathrm{~nm}$, whereas after $600 \mathrm{~s}$ it was further reduced to $206 \mathrm{~nm}$. In the following, the different PS-NS templates are referred to as $\mathrm{P} x(x=0,300,600$ depending on the $\mathrm{O}_{2}$ plasma etching duration). In Fig. 1(b-d), the SEM images of P0, P300 and P600 are presented.

After the successful preparation of the templates, we investigated two solution-based approaches to incorporate the metal sulfide, which are schematically illustrated in Fig. 2. In the first route, a solution containing a mixture of copper and indium xanthates was infiltrated into the nanostructure followed by an in situ thermal conversion to the metal sulfide. In the second route, an ink containing pre-synthesized thioglycerol-capped $\mathrm{CuInS}_{2}$ NCs was employed for the infiltration. The PS nanospheres were removed from the film either by a thermal decomposition process or dissolution to obtain the honeycombstructured thin films of $\mathrm{CuInS}_{2}$.

\section{b. Formation of honeycomb-structured films via in situ $\mathrm{CuInS}_{2}$ production - precursor route}

In this approach, the PS-NS template is infiltrated with a $\mathrm{CuInS}_{2}$ precursor solution consisting of a mixture of copper and indium xanthates (copper $O$-2,2-dimethylpentan-3-yl dithiocarbonate and indium O-2,2-dimethylpentan-3-yl dithiocarbonate). ${ }^{33}$ The challenge hereby is that these compounds are highly soluble in solvents such as chloroform and toluene, which also dissolve polystyrene. Consequently, polar solvents, such as ethanol, used in the formation of hexagonally-structured $\mathrm{TiO}_{2}$ and $\mathrm{SiO}_{2}$ with PS-NS templates, would be beneficial. ${ }^{23,24}$ However, ethanol does not dissolve the metal xanthates (in particular the copper xanthate shows very low solubility in polar solvents) and hence, according to a previous study, a solvent mixture of ethanol: dichloromethane: ethanolamine $(20: 10: 1$, vol. ratio) was used, in order to form a clear and stable precursor solution, while it does not dissolve the polystyrene template. ${ }^{37}$ The infiltration was realized by drop casting the solution onto the template film and soaking for several seconds followed by spinning off the excess amount of solution at a speed of $5000 \mathrm{rpm}$ using a spin coater. This assures a good infiltration of the template, without the formation of a noticeable continuous precursor film on top of the template.

After this step, the FT-IR spectrum (Fig. 3a) shows the vibrations of both the xanthates and the polystyrene, indicating that the infiltration procedure does not remove the template. Most of the vibration peaks appearing in the spectrum correspond to the xanthates. The high intensity peak at $2968 \mathrm{~cm}^{-1}$ correspond to the $\mathrm{C}-\mathrm{H}$ asymmetric stretching vibration, while the peaks at 1240 and $1214 \mathrm{~cm}^{-1}$ and at 1056 and at $1036 \mathrm{~cm}^{-1}$ correspond to asymmetric $\mathrm{C}-\mathrm{O}-\mathrm{C}, \mathrm{C}-\mathrm{S}$ and $\mathrm{C}-\mathrm{H}$ stretching vibrations of the xanthates, respectively. ${ }^{38}$ Regarding the polystyrene, lower intensity vibrations, which stem from an aromatic $\mathrm{C}-\mathrm{H}$ stretching vibration, can be observed at $3025 \mathrm{~cm}^{-1}$. The bands at 1601, 1493 and $1452 \mathrm{~cm}^{-1}$ correspond to aromatic $\mathrm{C}=\mathrm{C}$ stretching vibrations and the ones at 757 and $697 \mathrm{~cm}^{-1}$ to C-H out-of-plane bending vibrations. ${ }^{39}$

Subsequently, the metal xanthates are converted to copper indium sulfide by heating the samples to $195{ }^{\circ} \mathrm{C}$ under nitrogen atmosphere. The FT-IR spectrum of a sample heated to $195{ }^{\circ} \mathrm{C}$ does not reveal any vibration peaks related to the xanthates. All the peaks refer to polystyrene. Some were already mentioned before, while the ones at 2925 and $2843 \mathrm{~cm}^{-1}$ were superimposed by the high intensity xanthate peaks in the aforementioned spectrum. ${ }^{39}$ These vibration peaks correspond to the methylene group of polystyrene. Finally, the decomposition of polystyrene was accomplished at $400{ }^{\circ} \mathrm{C}$ under nitrogen. The corresponding FT-IR-spectrum does not show any vibrations in the range from $4000-400 \mathrm{~cm}^{-1}$, as all the organic material has been removed from the film.

A grazing incidence X-ray diffraction (GIXRD) measurement on the final film exhibits three broad diffraction peaks with low intensity at 28.1, 31.2 and $46.4^{\circ} 2 \theta$ indicating the formation of chalcopyrite $\mathrm{CuInS}_{2}$ (Fig. 3b). To confirm this result, we analysed $\mathrm{CuInS}_{2}$ powder prepared with a very similar procedure, with the only difference that the precursor solution was placed 


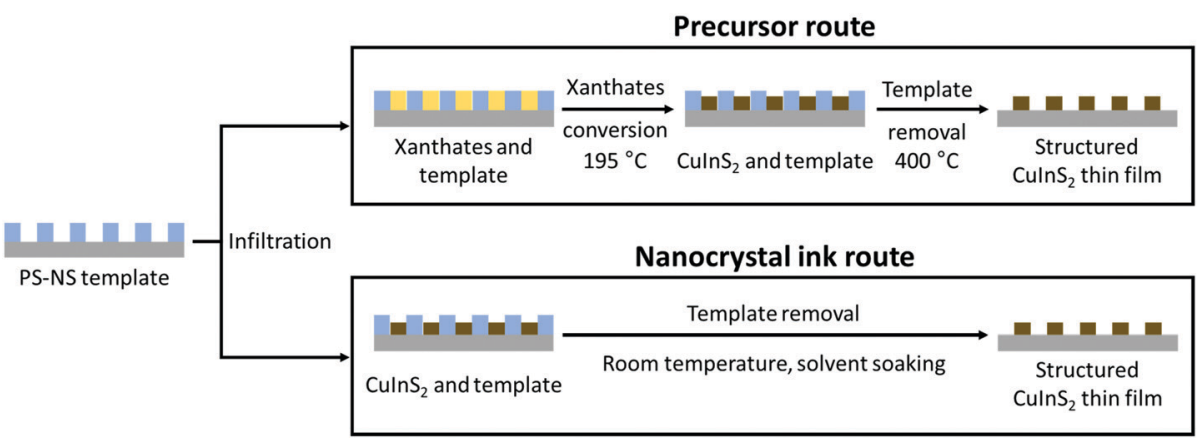

Fig. 2 Schematic presentation of the two PS-NS template routes based on (i) precursor infiltration/conversion and (ii) nanocrystal ink infiltration for the formation of honeycomb structured CulnS $_{2}$ thin films.
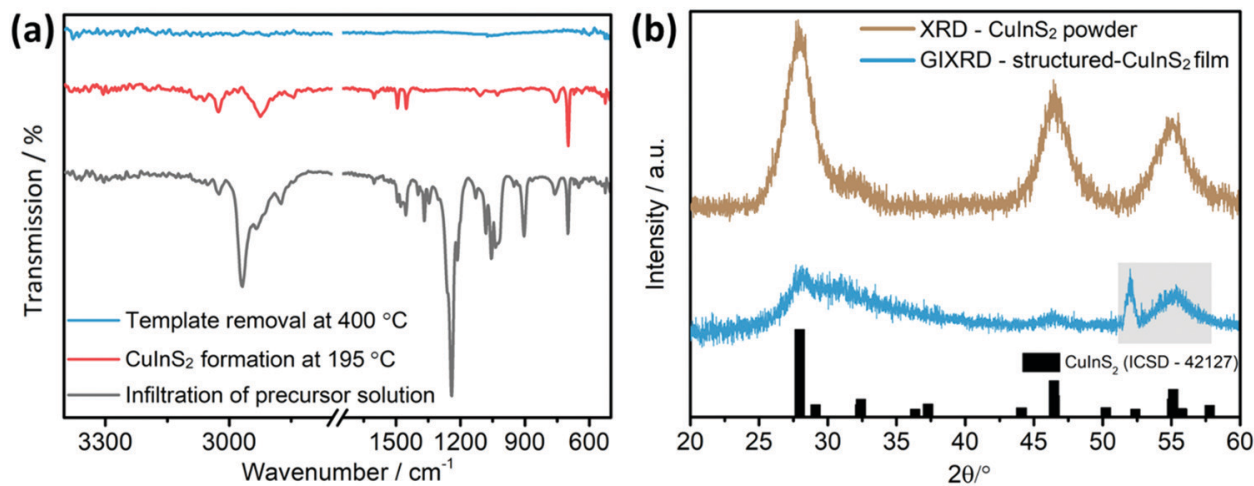

Fig. 3 (a) FT-IR spectra after infiltration of the PS-NS template with the precursor solution (grey), after CulnS ${ }_{2}$ formation at $195{ }^{\circ} \mathrm{C}$ (red) and after template removal via thermal decomposition at $400{ }^{\circ} \mathrm{C}$ (blue). (b) Powder X-ray diffraction (PXRD, brown) and grazing incidence X-ray diffraction (GIXRD, blue) patterns of the $\mathrm{CulnS}_{2}$ powder and the structured $\mathrm{CulnS}_{2}$ film on a silicon substrate, respectively, obtained by decomposition of the xanthate precursors at $400{ }^{\circ} \mathrm{C}$ with a reference pattern for the chalcopyrite CulnS 2 structure (ICSD-42127). The grey frame on the GIXRD pattern indicates the silicon diffraction peaks stemming from the substrate. The IR spectra and diffraction patterns are shifted vertically for better visibility.

in a glass container, dried and annealed at $400{ }^{\circ} \mathrm{C}$ under nitrogen atmosphere to yield a higher amount of material. The obtained pattern exhibits also the typical diffraction peaks of $\mathrm{CuInS}_{2}$ at 28.0 (112), 32.4 (200), 46.4 (204) and 55.1 $2 \theta$ (312) (reference pattern for chalcopyrite $\mathrm{CuInS}_{2}$ structure: ICSD-42127). Furthermore, the broadness of the peaks indicates the formation of nanosized $\mathrm{CuInS}_{2}$ particles. Additionally, from a SEM-EDX analysis of the films (Fig. S2, ESI $\dagger$ ) an elemental composition of $\mathrm{Cu}: \mathrm{In}: \mathrm{S}$ of $1: 0.8: 1.8$ (atomic ratio) was obtained, which is close to the stoichiometric $1: 1: 2$ ratio taking also the uncertainty of the SEM-EDX measurement of thin films into account.

This heating process to convert the precursors into $\mathrm{CuInS}_{2}$ and to remove the template is a central step in the formation of the honeycomb structured films. Therefore, it was analysed by time resolved grazing incidence wide and small angle X-ray scattering (GIWAXS, GISAXS) using synchrotron radiation and compared to the preparation of a bulk (non-structured) $\mathrm{CuInS}_{2}$ film from the same metal xanthates as starting material. The extracted GIWAXS patterns and GISAXS images obtained at various temperatures during the heating run from 35 to $400{ }^{\circ} \mathrm{C}$ (heating rate: $10{ }^{\circ} \mathrm{C} \mathrm{min}^{-1}$ ) are depicted in Fig. 4 and 5 . Moreover, the GISAXS patterns in in-plane and out-of-plane direction are shown in Fig. S4, ESI. $\dagger$
The GIWAXS patterns (Fig. 4) and the corresponding surface plots (Fig. S5, ESI $\dagger$ ) illustrate the formation of $\mathrm{CuInS}_{2}$ through the evolution of the (112) reflection of $\mathrm{CuInS}_{2}$, which is located at $28.0^{\circ} 2 \theta$. At a temperature of $35^{\circ} \mathrm{C}$, no diffraction peaks are visible, while a broad peak appears at a temperature of $130-135{ }^{\circ} \mathrm{C}$. This broad peak is shifted to higher $2 \theta$ values (peak maximum at $29-30^{\circ} 2 \theta$ ) compared to the position of the (112) reflection of $\mathrm{CuInS}_{2}$. This indicates the formation of $\mathrm{CuS}$ seeds (reference pattern of covellite CuS, COD ID: 9000062), before the formation of the $\mathrm{CuInS}_{2}$ nanocrystals. At approx. $150-160{ }^{\circ} \mathrm{C}$, the peak becomes significantly narrower and the position shifts to lower $2 \theta$ values, which corresponds to the typical peak position of chalcopyrite $\mathrm{CuInS}_{2}$ nanocrystals. This phenomenon is known for nanocrystal synthesis in solution, ${ }^{40}$ however, has not been observed so far in solventless conversion processes. Both the bulk and structured film display the same behaviour regarding the nanocrystal formation, but the formation of the CuS nanocrystals as well as the transformation to the $\mathrm{CuInS}_{2}$ nanocrystals occurs at slightly $\left(5-10{ }^{\circ} \mathrm{C}\right)$ higher temperatures in the structured film, most presumably due to the presence of the PS template and the thereby decelerated heat transfer through the film. The sharp peaks visible in Fig. 4 and Fig. S5 (ESI $\dagger$ ) at $2 \theta$ values of 27.8 and $28.9^{\circ}$ at certain 

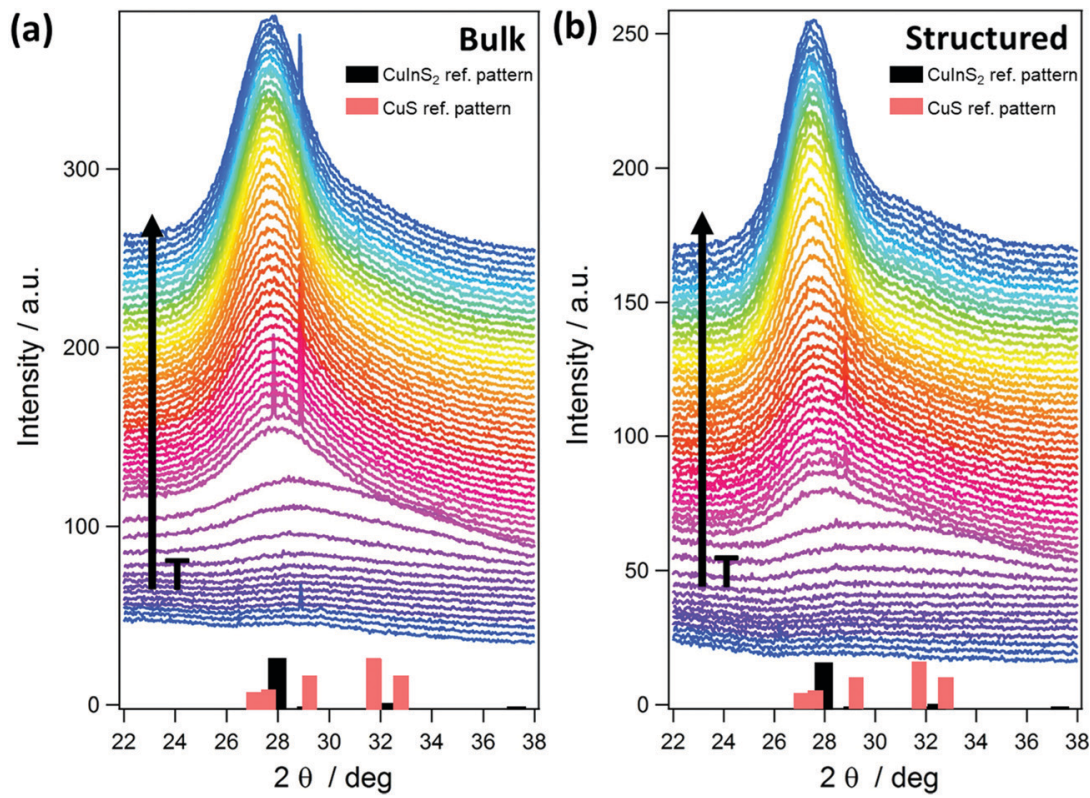

Fig. 4 GIWAXS patterns of (a) bulk (non-structured) and (b) structured thin films measured between 22 and $38^{\circ} 2 \theta$ during heating runs from 35 up to $400{ }^{\circ} \mathrm{C}$ with a heating rate of $10{ }^{\circ} \mathrm{C} \mathrm{min}{ }^{-1}$ and subsequent annealing of $15 \mathrm{~min}$ at $400{ }^{\circ} \mathrm{C}$, displaying the formation of the (112) reflection of CulnS $\mathrm{C}_{2}$ centred at $28.0^{\circ} 28$. Columns in the graph correspond to reference patterns of chalcopyrite CulnS 2 structure (ICSD-42127) and covellite CuS (COD ID: 9000062). The increasing temperature $(T)$ is indicated with a black arrow and the curves are shifted vertically for better visibility.

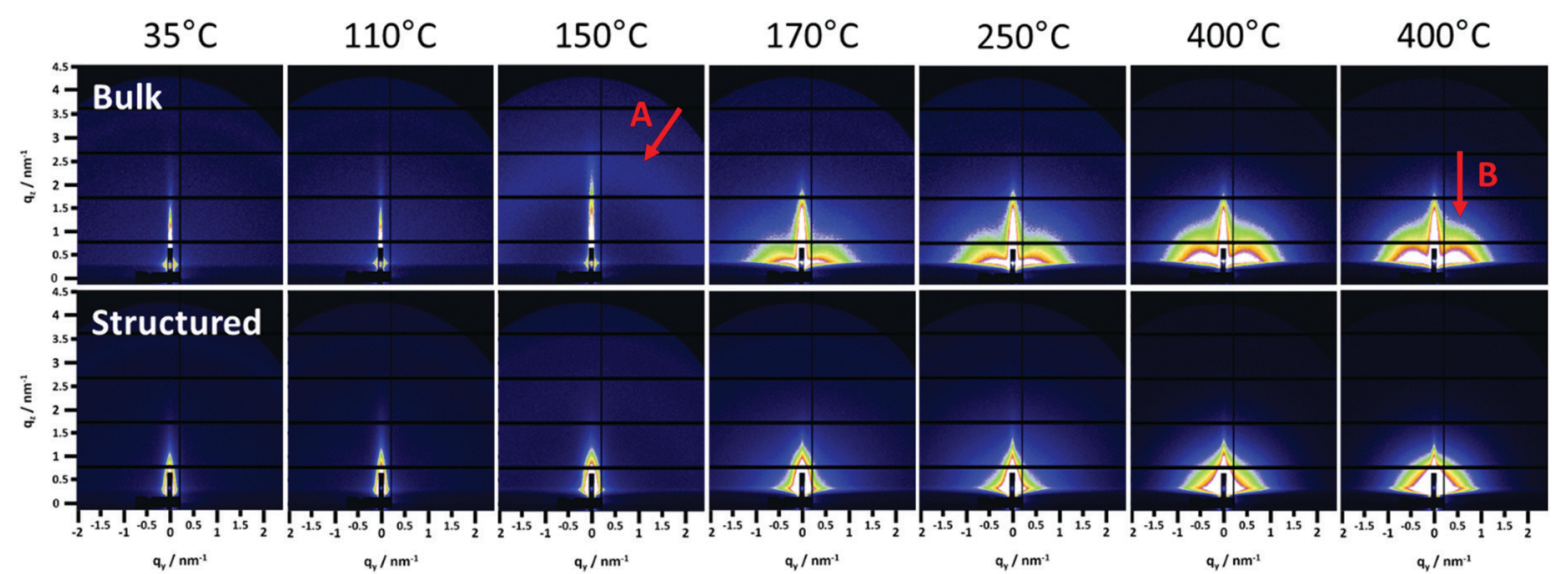

Fig. 5 GISAXS patterns of the bulk (top) and structured (bottom) films at different temperatures starting from 35 up to $400{ }^{\circ} \mathrm{C}$ and 15 min annealing. Arrow $\mathrm{A}$ shows a semicircle like feature indicating a high order in the bulk film and arrow $\mathrm{B}$ points to the feature indicating the preferential near range order of the $\mathrm{CulnS}_{2}$ nanoparticles in the in-plane direction.

temperatures during the heating originate very likely from silicon crystals (impurity due to substrate cutting and handling) occasionally moving into the reflection conditions in these temperature ranges and are not stemming from the investigated $\mathrm{CuInS}_{2}$ thin films.

Further information can be extracted from the GIWAXS invariant and the evolution of the primary crystallite size determined using the Scherrer formula and the FWHM of the (112) reflection of $\mathrm{CuInS}_{2}$, as well as the GISAXS (Porod) invariant and correlation length ${ }^{41}$ shown in Fig. 6. The calculation of the invariant values as well as the correlation length is outlined in the ESI. $\dagger$
The onset of the conversion and the evaporation of organic decomposition products from the film leading to an increased electron density are indicated by an increase in the GIWAXS and GISAXS invariant at $114{ }^{\circ} \mathrm{C}$ (Fig. 6, arrow A) and the main conversion process is completed at $179{ }^{\circ} \mathrm{C}$ (arrow B). At that point, the primary crystallite size is $3.4 \mathrm{~nm}$ in the nonstructured as well as the structured film. This fast conversion and nanocrystal growth are followed by a slower growth phase until approximately $300{ }^{\circ} \mathrm{C}$. At this temperature the growth rate increases again and we assume that this phenomenon is based on an Ostwald ripening-type growth mechanism. However, it is apparent that in the case of the structured film, this step is 
(a) Bulk

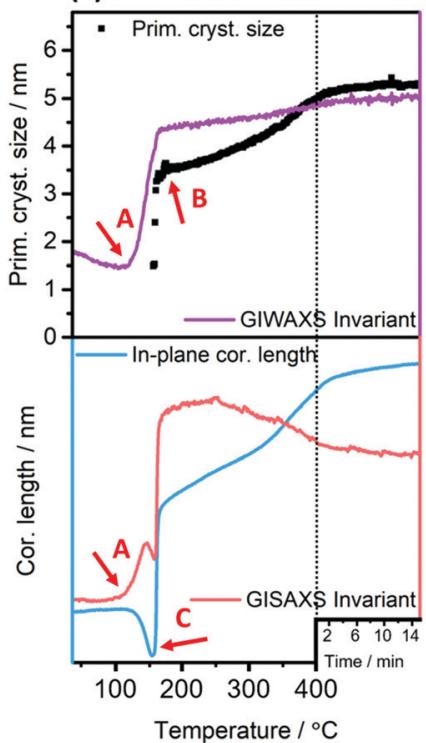

(b) Structured

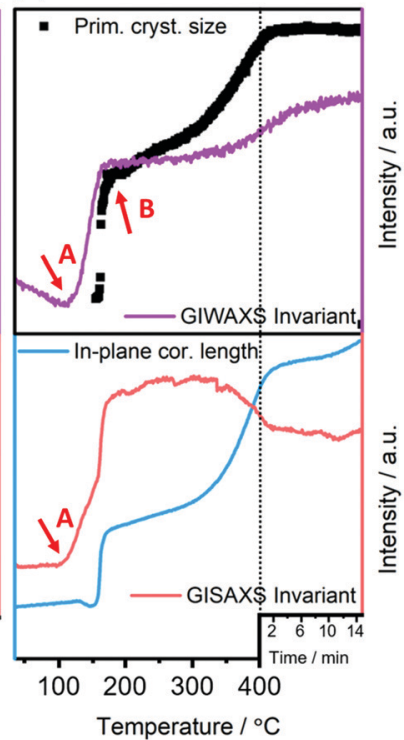

Fig. 6 From top to bottom: GIWAXS invariant (purple) and the evolution of primary crystallite size (black) and GISAXS in-plane correlation length (blue) and invariant (red) during the heating run for (a) bulk as well as (b) structured films. Arrows A, B and C indicate the thermal conversion onset offset and mesophase onset, respectively. The dashed lines denote the beginning of the annealing at constant temperature $\left(400^{\circ} \mathrm{C}\right)$ for $15 \mathrm{~min}$.

much more pronounced (see Fig. 6a and b). This behaviour originates most likely from the combination of the Ostwald ripening-type mechanism and the decomposition of the polystyrene, which also starts at approximately $300{ }^{\circ} \mathrm{C} .{ }^{42}$ We assume that polystyrene acts as a matrix for the $\mathrm{CuInS}_{2}$ at least in interfacial regions, which hinders the crystal growth, while upon its removal, the crystallite size remarkably increases. This assumption can be supported by the SEM images in Fig. S6 (ESI $\dagger$ ) showing the structured film after the $\mathrm{CuInS}_{2}$ formation at $195{ }^{\circ} \mathrm{C}$ and before the polystyrene removal. The images illustrate a rather planar surface, where a hexagonal structure is distinguished underneath. Clear polystyrene sphere structures, however, are not visible after heating the film to $195{ }^{\circ} \mathrm{C}$ because the glass transition temperature of polystyrene has been exceeded. ${ }^{43}$ At $400{ }^{\circ} \mathrm{C}$, primary crystallite sizes of $5.3 \mathrm{~nm}$ and $6.3 \mathrm{~nm}$ are obtained in the bulk and the structured films, respectively. The larger crystallite sizes in the structured film can be ascribed to the extended second growth phase (Ostwald ripening, growth after removal of polystyrene).

Moreover, the GISAXS images (shown for the bulk and structured films at different temperatures in Fig. 5) reveal additional information. In the bulk film, upon the xanthate conversion, an ordered mesophase is formed at approximately $150{ }^{\circ} \mathrm{C}$ by the decomposition products. This is indicated by a low intensity semicircle like feature (arrow A in Fig. 5), which is characteristic for an ordered phase, and also by the distinct minimum in the in-plane correlation length in Fig. 6(a) (bottom row, arrow $\mathrm{C}$ ). While a minimum in the in-plane correlation length can also be recognized in the structured film, it is much less pronounced. Based on a previous study on a closely related materials system, ${ }^{44}$ we ascribe this mesophase to an ordered structure formed by the decomposition products of the metal xanthates during the first stage of the nanocrystal growth.

Additionally, the GISAXS image of the bulk film at $400{ }^{\circ} \mathrm{C}$ (arrow B in Fig. 5) indicates a preferential near range order of the $\mathrm{CuInS}_{2}$ nanocrystals in the in-plane direction. On the contrary, in the structured film, this preferential near range order is not observed.

In general, the concentration of the precursor solution, the spin coating speed and the drying process of the films are very important parameters in the formation of the $\mathrm{CuInS}_{2}$ honeycomb nanostructure. As an example, in Fig. S7 (ESI $\dagger$ ) the FT-IR spectra and SEM images of films prepared with too high precursor concentration and too low spin coating speed are presented. The FT-IR spectrum before annealing shows both the PS-NS template and the xanthates, but the film was still not completely dry, as it is also indicated by the vibration peak at $3358 \mathrm{~cm}^{-1}$ corresponding to the OH-group of ethanol. ${ }^{45}$ This also significantly affects the final nanostructure, as the SEM images of these films only partly reveal the expected negative of the PS-NS template and also larger areas of compact CuInS films are formed on top of the template.

Based on these considerations, the reduction of the precursor concentration and the insertion of an additional drying step of the films at $90{ }^{\circ} \mathrm{C}$ for several minutes, between the infiltration and the decomposition step (heating ramp to $400{ }^{\circ} \mathrm{C}, 15 \mathrm{~min}$ holding time), led to well-defined honeycomb structures in case of the P300 and P600 templates. The SEM images in Fig. 7 illustrate the successful formation of honeycomb-structured $\mathrm{CuInS}_{2}$ films, which are in the following referred to as CIS-P $x$ depending on the used nanosphere array template. In case of CIS-P300 and CIS-P600, homogeneous and ordered hexagonally-structured $\mathrm{CuInS}_{2}$ arrays were achieved. In the case of the CIS-P0 sample, no formation of a well-defined honeycomb structure could be obtained as still areas of $\mathrm{CuInS}_{2}$ films were formed above the honeycomb structure, leading to an inhomogeneous film surface (Fig. 7b). This is due to the tightly hexagonally packed PS nanospheres, which hinder the infiltration of sufficient amounts of the precursor solution.

As it can be clearly seen from the values in Table 1 , the results of plasma etching have a pronounced impact on the dimensions of the nanostructures in the films. The wall thickness is higher for CIS-P600 (approx. $70 \mathrm{~nm}$ compared to $59 \mathrm{~nm}$ in the CIS-P300 sample), where a longer plasma etching process was applied leading to larger interstitial space between the spheres for the infiltration of the precursors and consequently also to smaller cell diameters. While in the CIS-P300 film cell diameters of $315 \mathrm{~nm}$ are observed, cell diameters of $234 \mathrm{~nm}$ are generated in the CIS-P600 sample.

Alternative methods to remove the template at lower temperatures did not lead to the expected result. For example, while thermal annealing of the sample at $280{ }^{\circ} \mathrm{C}$ in air resulted in the removal of the PS nanospheres, the remaining honeycomb structure was significantly oxidized. Moreover, soaking of the sample in chloroform after the conversion of the metal 

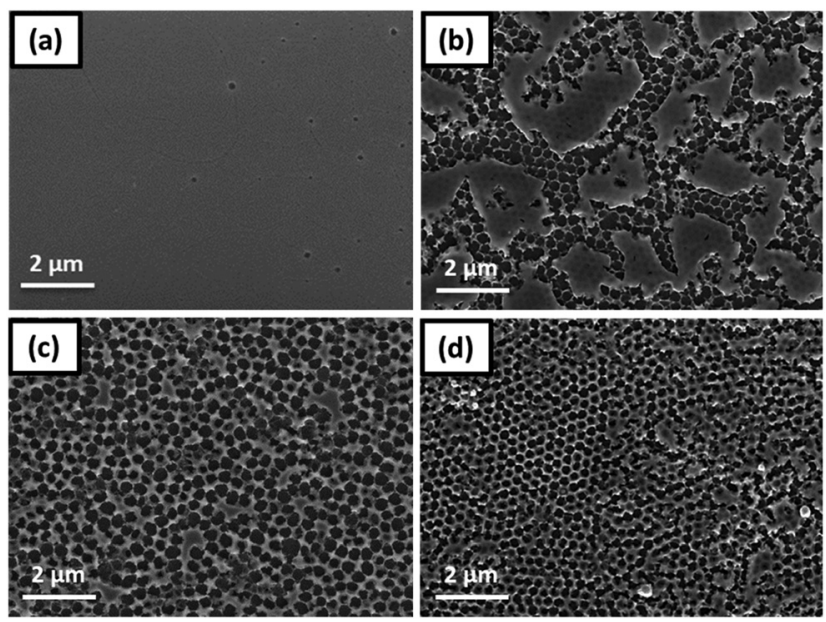

Fig. 7 SEM images of (a) bulk-CIS (b) CIS-PO, (c) CIS-P300 and (d) CISP600 after annealing at $400{ }^{\circ} \mathrm{C}$.

Table 1 The cell diameter, wall width and film thickness of the CIS-P300, CIS-P600 and bulk-CIS, derived by the precursor route

\begin{tabular}{lccl}
\hline Precursor route & CIS-P300 & CIS-P600 & Bulk-CIS \\
\hline Cell diameter $(\mathrm{nm})$ & $315 \pm 35$ & $234 \pm 21$ & - \\
Wall thickness $(\mathrm{nm})$ & $59 \pm 21$ & $70 \pm 14$ & - \\
Film thickness $(\mathrm{nm})$ & $98 \pm 5$ & $101 \pm 5$ & $26 \pm 1$
\end{tabular}

xanthates to $\mathrm{CuInS}_{2}$ at $195{ }^{\circ} \mathrm{C}$ led to an incomplete removal of the template. Details to these processes are summarized in the ESI. $\dagger$

\section{c. Formation of honeycomb-structured films via stabilized CuInS $_{2}$ NCs - nanocrystal ink route}

To realize the formation of honeycomb-structured $\mathrm{CuInS}_{2}$ films at low temperatures, we followed a second approach, which is based on the idea of forming the strctured thin films by employing already prepared capped $\mathrm{CuInS}_{2}$ NCs. Thus, a presynthesized and stabilized $\mathrm{CuInS}_{2}$ nanocrystal ink is used for infiltration of PS-NS templates. This provides an advantage during the formation of the $\mathrm{CuInS}_{2}$-scaffold in comparison to the in situ decomposition of the xanthates, in which a large amount of the decomposition products are leaving during the formation of the metal sulfide structures.

The synthesis of the NCs was carried out by using copper and indium xanthates as precursors according to a previous study via a hot injection process and dioleamide (oleyl oleamide, $N$-((Z)-octadec-9-en-1-yl)oleamide) as capping ligand. ${ }^{32}$ The dioleamide is formed from the reaction of the oleylamine and oleic acid, ${ }^{46}$ while it stabilizes the NCs through the amide

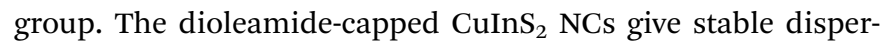
sions in solvents, such as chloroform and toluene. However, the problem with these solvents is, as mentioned earlier, that they are not suitable for the infiltration of PS-NS templates. As the nature of the capping ligand plays an important role on the solubility of the nanocrystals, we modified the nanocrystals by a ligand exchange. Thiols are known as good capping ligands for the metal sulfide nanocrystals, specifically for quantum dots (QDs) due the crystal-bound ability, which means that the sulfur can actively participate in the surface of the crystal. ${ }^{47}$ Due to the strong binding, the thiol ligands cannot be easily replaced by other ligands, but they can easily replace other ligands, such as amine-based ligands. ${ }^{48}$ Thus, we exchanged the bulky dioleamide ligand by 1-thioglycerol (TG) via a ligand exchange procedure at $90{ }^{\circ} \mathrm{C}$ for $24 \mathrm{~h}$. The thioglycerol-capped NCs form stable colloidal dispersions in solvents such as DMSO and DMF. Hence, we prepared NC inks in DMSO, which can be used for infiltration of the templates. Fig. 8 represents the process of the dioleamide-capped $\mathrm{CuInS}_{2}$ nanocrystal formation via hot injection and the subsequent ligand exchange with the thioglycerol.

The FT-IR spectra of the dioleamide-capped NCs show vibrations at 1648 and $1563 \mathrm{~cm}^{-1}$, which correspond to $\mathrm{C}=\mathrm{O}$ group stretching and $\mathrm{N}-\mathrm{H}$ group bending vibrations, as well as at 3307 and $3009 \mathrm{~cm}^{-1}$ that belong to the $\mathrm{N}-\mathrm{H}$ group stretching vibration and to the amide group, respectively. Additionally, the XRD results reveal the typical diffraction peaks of the $\mathrm{CuInS}_{2}$ chalcopyrite crystal structure (ICSD-42127), while from the peak broadening and the Scherrer equation, a nanocrystal size of approximately $3.6 \mathrm{~nm}$ was determined, which also fits with previous studies. $^{14,32}$

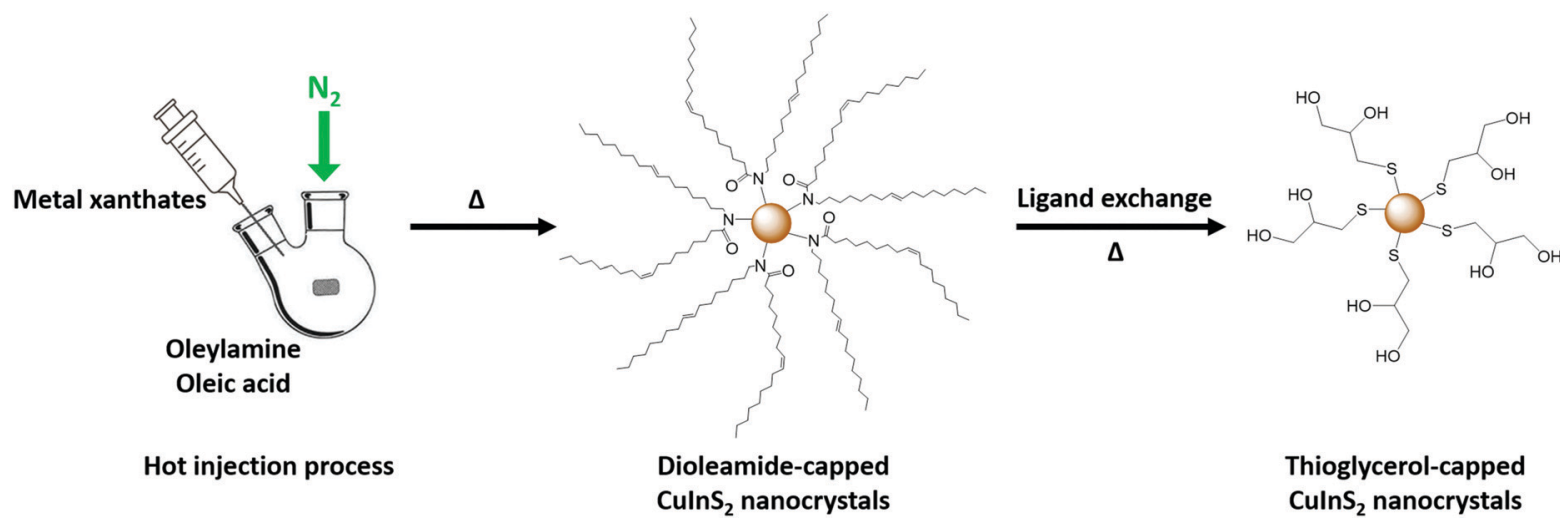

Fig. 8 Representation of the dioleamide-capped NCs synthesis and ligand exchange with 1-thioglycerol. 

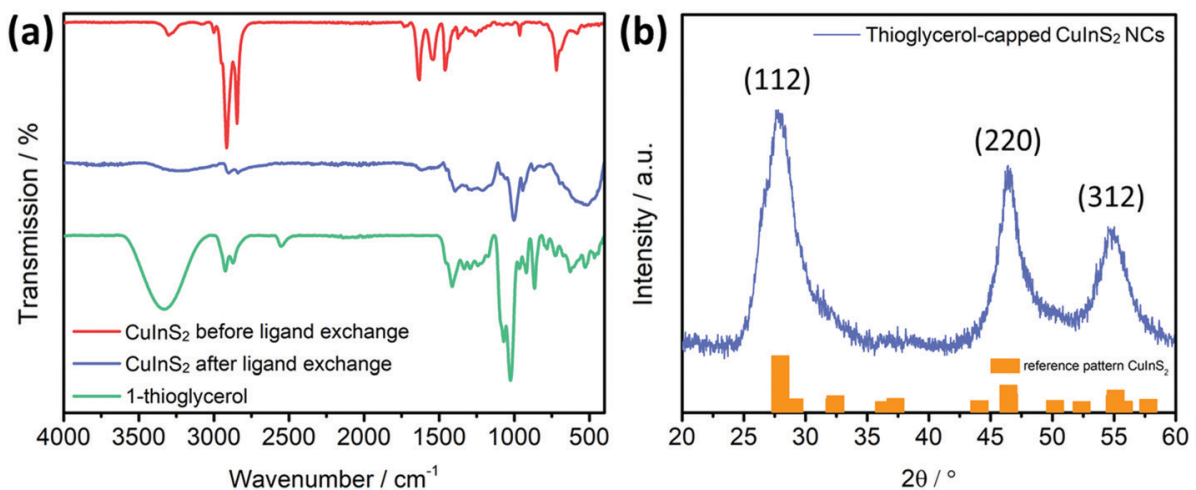

Fig. 9 (a) FT-IR spectra before (red spectrum) and after the ligand exchange (blue spectrum) and free 1-thioglycerol (green spectrum). The spectra are shifted vertically for better visibility. (b) X-Ray diffraction pattern of the $\mathrm{CulnS}_{2}$ nanocrystals after ligand exchange, with reference patterns for chalcopyrite CulnS $_{2}$ (ICSD-42127)

In order to investigate the success of the ligand exchange, an FT-IR measurement was performed. The FT-IR spectra in Fig. 9(a) illustrate the results before and after the exchange, as well as the free 1-thioglycerol. The spectrum after the exchange fits quite well with the free 1-thioglycerol, indicating the successful replacement of the dioleamide ligand. Specifically, the broad peak at $3331 \mathrm{~cm}^{-1}$ corresponds to the stretching vibration of $\mathrm{OH}$-group, while the absence of the peak at $2554 \mathrm{~cm}^{-1}$, which belongs to the stretching vibration of the SH-group, reveals that there is no unbound thioglycerol present. Simultaneously, the XRD pattern after the ligand exchange resembles the one before the exchange (Fig. S11, ESI $\dagger$ ), while the crystal size is determined to be also approximately $3.6 \mathrm{~nm}$, meaning that the process does not influence the size. Lastly, the UV-vis absorption spectra of the NCs before and after ligand exchange in Fig. S12 (ESI $\dagger)$, illustrate the typical absorption curve of the $\mathrm{CuInS}_{2}$ nanocrystals with an absorption onset at approximately $850 \mathrm{~nm}$, corresponding to an optical band gap of $1.45 \mathrm{eV}$.

In the next step, the PS-NS template P600 was infiltrated with the $\mathrm{CuInS}_{2}$ nanocrystal ink in DMSO. Specifically, the $\mathrm{CuInS}_{2}$ ink with a concentration $100 \mathrm{mg} \mathrm{mL}^{-1}$ was infiltrated via a few seconds of soaking followed by spin coating with $1000 \mathrm{rpm}$ rotation speed. After a drying process of the samples at $90{ }^{\circ} \mathrm{C}$, the samples were immersed in toluene for the template removal. The FT-IR spectra in Fig. 10(a) display the characteristics before and after immersion. In both spectra, only the vibration bands of the polystyrene are identified. A potential explanation for the absence of vibrations, which correspond to the thioglycerol-capped $\mathrm{CuInS}_{2}$, could be the low intensity signals of the initial material, as it can be seen in Fig. 9(a) in comparison to the signals of the free 1-thioglycerol. This, in combination with the usage of a low concentration of the ink, leads to the lack of vibrational bands corresponding to the stabilized NCs. Moreover, after the immersion of the samples in toluene, it is noticed that polystyrene remains on the film. However, the intensity of the signals is significantly reduced, indicating that the template is widely removed. The remaining bands in the IR spectrum can be attributed to trapped polystyrene among the NCs. The SEM image in Fig. 10(b) shows that the procedure was successful, resulting in well-defined hexagonal-structured thin films. Information regarding the pore diameter, wall and film thickness are summarized in Table 2 . The cell $(\sim 264 \mathrm{~nm})$ and wall sizes $(\sim 78 \mathrm{~nm})$ fit well with the values obtained for the CIS-P600 with the precursor route, as in both cases the P600 PS-NS template was used. Moreover, the GIXRD pattern of the structured film (Fig. S14, ESI $\dagger$ ) reveals a broad peak around $28^{\circ} 2 \theta$
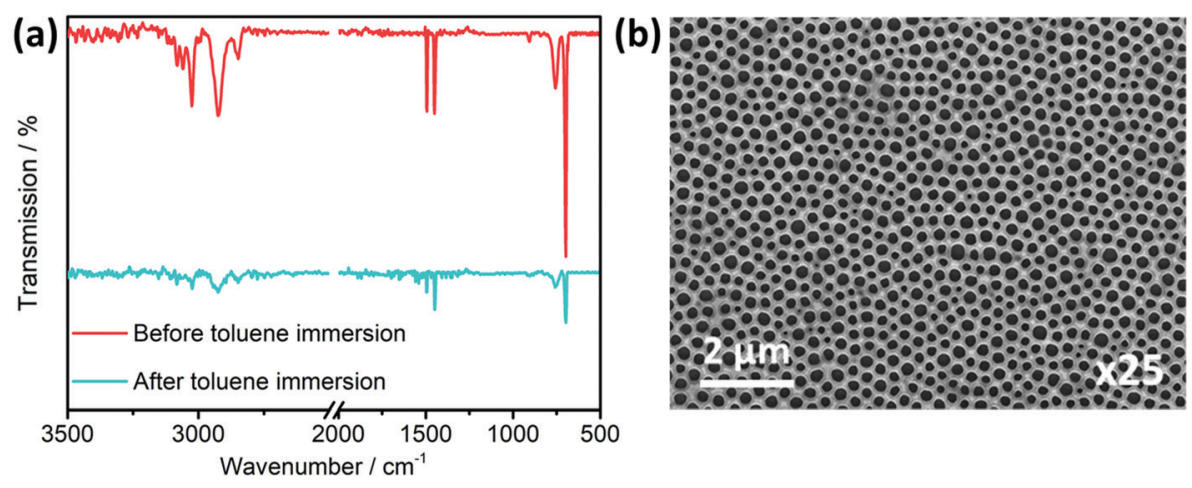

Fig. 10 (a) FT-IR spectra of thin films before and after immersion of the infiltrated thin films in toluene. The spectra are shifted vertically for better visibility. (b) SEM images of the honeycomb-structured CulnS 2 thin films after template removal. 
Table 2 The cell diameter, wall width and film thickness of the structured$\mathrm{CulnS}_{2}$ thin film, derived by the nanocrystal ink route

Nanocrystal ink route

\begin{tabular}{lc}
\hline Cell diameter $(\mathrm{nm})$ & $264 \pm 30$ \\
Wall thickness (nm) & $78 \pm 17$ \\
Film thickness (nm) & $75 \pm 2$
\end{tabular}

stemming from the 112 reflection of the chalcopyrite crystal structure of the $\mathrm{CuInS}_{2}$ nanocrystals. Similar to the structured films prepared via the precursor route, these samples also display a structural colour. After the infiltration of the NCs, the films do not appear coloured, because there is no defined structure. On the contrary, when the template is removed, the inverse structure of the $\mathrm{CuInS}_{2}$ NCs remains and hence, the films appear blue (see Fig. S13, ESI $\dagger$ ).

\section{Conclusion}

In summary, we developed two novel, cost-efficient and scalable routes towards the formation of honeycomb-structured $\mathrm{CuInS}_{2}$ thin films via nanosphere colloidal lithography. A mixture of copper and indium xanthates, as metal sulfide precursors was used in the first route for the in situ formation of $\mathrm{CuInS}_{2}$. For the second route pre-synthesized thioglycerol-capped $\mathrm{CuInS}_{2}$ NCs were employed. The PS-NS template layer was fabricated via an air/liquid interface method and subsequently modified with $\mathrm{O}_{2}$ plasma etching. The plasma etching was essential for increasing the interstitial space between the spheres and hence, facilitating the infiltration process.

In the first route, the infiltration of the template with the metal xanthate solution was followed by the in situ formation of the nanocrystalline $\mathrm{CuInS}_{2}$ through the thermal decomposition of the xanthate mixture at $195{ }^{\circ} \mathrm{C}$. The conversion to the metal sulfide starts already at $114{ }^{\circ} \mathrm{C}$, a temperature at which the PS-NS template is stable. By further heating to $400{ }^{\circ} \mathrm{C}$, the PS template is removed, resulting in a well-defined honeycombstructured $\mathrm{CuInS}_{2}$ film.

For the second approach, dioleamide-capped $\mathrm{CuInS}_{2} \mathrm{NCs}$ were first synthesized via a hot injection synthesis followed by a ligand exchange leading to thioglycerol-capped $\mathrm{CuInS}_{2}$ NCs. The thioglycerol ligands enabled the infiltration of the PS-NS templates with a DMSO based nanocrystal ink, which was not possible with the dioleamide-capped $\mathrm{CuInS}_{2} \mathrm{NCs}$, as they are only soluble in solvents, which also readily dissolve polystyrene. In this route, an annealing step after the infiltration could be omitted and thus a good solubility of the template is retained. After dissolving the template at room temperature in toluene, the honeycomb structured metal sulfide film is obtained.

\section{Experimental section}

All chemicals and solvents were used as purchased without any additional purification: dichloromethane $(\geq 99.8 \%$, Fisher
Chemical), dichlorobenzene (CHROMASOLV ${ }^{\mathbb{R}}, 99 \%$, SigmaAldrich), toluene ( $\geq 99 \%$ ), methanol (VWR), ethanol ( $\geq 99.8 \%$, Sigma-Aldrich), dimethyl sulfoxide (DMSO, $\leq 0.02 \%$ water, Sigma-Aldrich), hexane $(\geq 99 \%)$, polystyrene nanospheres (Latex beads, LB3, $0.3 \mu \mathrm{m}$ mean particle size), sodium dodecyl sulfate (SDS, $\geq 95 \%$, ROTH), ethanolamine ( $\geq 99 \%$, SigmaAldrich), oleylamine (approximate C18-content 80-90\%, ACROS ORGANICS), oleic acid (technical grade 90\%, Sigma-Aldrich) and 1-thioglycerol ( $\geq 97 \%$, Sigma-Aldrich). Copper and indium xanthates (copper and indium O-2,2-dimethylpentan-3-yl dithiocarbonate, respectively) were synthesized according to a previous work. ${ }^{33}$

\section{a. Preparation of the polystyrene nanosphere templates}

The polystyrene nanosphere templates (PS-NS) with sphere sizes of approximately $300 \mathrm{~nm}$ were prepared by a selfassembly approach at the air/water interface, according to previous work. ${ }^{49}$ The detailed process is described below. A 1:1 volume ratio of an aqueous PS colloidal suspension with ethanol was prepared and was dispersed for 10 minutes in a sonication bath. Subsequently, the suspension was dropped $(\sim 100 \mu \mathrm{L})$ onto a glass slide $(1.5 \times 1.5 \mathrm{~cm})$, which was placed in the centre of a glass Petri dish. Deionized water was slowly added until a convex shape was formed around the glass slide, where the PS suspension was rapidly spread on the water/air interface, leading to the two-dimensional layer assembly. In order to closely-pack the polystyrene layer, a few drops of $2 \mathrm{wt} \%$ SDS aqueous solution were added. A large area of a blueish PS layer (structural color) at the air/liquid interface was observed, which indicated the formation of the closely-packed layer. To transfer the PS closely-packed layer on the substrate (glass and Si substrates), the latter was inserted beneath the floating layer and carefully lifted off from the water. Finally, the wet layers were dried at room temperature for several hours. After drying, PS-NS layers were transferred into an $\mathrm{O}_{2}$ plasma reactor chamber (FEMTO, Diener Electronic) for size modification. The $\mathrm{O}_{2}$ plasma etching was performed for 0,300 and $600 \mathrm{~s}$ under an excitation frequency of $40 \mathrm{kHz}$, a power of $100 \mathrm{~W}$ and a gas flow of $20 \mathrm{sccm}$.

\section{b. Preparation of honeycomb-structured films via in situ $\mathrm{CuInS}_{2}$ formation}

The honeycomb-structured $\mathrm{CuInS}_{2}$ films were fabricated by spin coating of the $\mathrm{CuInS}_{2}$ precursor solution. The solution was prepared by dissolving copper $O$-2,2-dimethylpentan-3-yl dithiocarbonate $\left(16.1 \mathrm{mg} \mathrm{mL}^{-1}, 1\right.$ equiv.) and indium $O-2,2-$ dimethylpentan-3-yl dithiocarbonate $\left(73.9 \mathrm{mg} \mathrm{mL}^{-1}, 1.7\right.$ equiv.) in a solvent mixture of 1000:500:50 $\mu \mathrm{L}$ ethanol:dichloromethane:ethanolamine. The solution is stable for approximately $4 \mathrm{~h}$, thus the infiltration should be completed directly after its preparation. The infiltration of the PS-NS templates was performed by spin-coating of the precursor solution (5000 rpm rotation speed, $60 \mathrm{~s}$ ). The infiltrated samples were then dried on a hot plate at $90{ }^{\circ} \mathrm{C}$ under ambient atmosphere for $10 \mathrm{~min}$. Finally, the samples were annealed at $400{ }^{\circ} \mathrm{C}$ (heating rate $10{ }^{\circ} \mathrm{C} \mathrm{min}^{-1}$ ) for $15 \mathrm{~min}$ under inert atmosphere, 
in order to form the CuInS 2 , decompose the PS-NS and result the honeycomb-CuInS $\mathrm{S}_{2}$ films. Additionally, bulk $\mathrm{CuInS}_{2}$ films were prepared following the same procedure, but a lower amount of solvent in a slightly adjusted mixture was used (700:350:50 $\mu \mathrm{L}$ ethanol: dichloromethane: ethanolamine) for dissolving the copper and indium xanthates $(16.1 \mathrm{mg}$ and $73.9 \mathrm{mg}$, respectively) to obtain higher film thicknesses.

\section{c. Nanocrystal synthesis}

$5 \mathrm{~mL}$ oleylamine and $5 \mathrm{~mL}$ oleic acid were placed in a threeneck round bottom flask with a stirrer and heated to $200{ }^{\circ} \mathrm{C}$ under inert conditions. A total amount of $0.5 \mathrm{mmol}$ of the copper and indium $\mathrm{O}$-2,2-dimethylpentan-3-yl-dithiocarbonate $\left(\mathrm{Cu}(\mathrm{Hep})\right.$ and $\mathrm{In}(\mathrm{Hep})_{3}$, respectively) in a ratio of $1: 1.7$ were dissolved in $3 \mathrm{~mL}$ dichlorobenzene and injected in the hot reaction mixture and kept for $30 \mathrm{~min}$. Subsequently, the mixture was left to cool down naturally to room temperature. By addition of methanol, the nanocrystals were precipitated and collected by centrifugation. The solid material was redispersed in toluene, precipitated with methanol and collected again by centrifugation. The clean solid was finally dispersed in toluene.

\section{d. Ligand exchange}

The $\mathrm{CuInS}_{2}$ nanocrystals capped with the dioleamide (product of oleylamine and oleic acid at high temperatures) ligand were put in $4 \mathrm{~mL}$ of 1-thioglycerol and heated to $90{ }^{\circ} \mathrm{C}$ under nitrogen atmosphere. After $24 \mathrm{~h}$ stirring, the solution was cooled down to room temperature and purified by a dichloromethane/hexane mixture. The precipitated material was collected by centrifugation. Subsequently, the solid was redispersed in DMSO, precipitated and centrifuged. The final material was dispersed in DMSO.

\section{e. Preparation of honeycomb-structured films via stabilized $\mathrm{CuInS}_{2}$ NCs}

The honeycomb-structured thin films were formed by using the thioglycerol-capped CuInS 2 nanocrystals in DMSO. The dispersion with a concentration of $100 \mathrm{mg} \mathrm{mL}^{-1}$ was infiltrated in the PS-NS templates by spin coating at $1000 \mathrm{rpm}$ for $60 \mathrm{~s}$. The infiltrated samples were then dried on a hot plate at $90{ }^{\circ} \mathrm{C}$ under ambient atmosphere for $10 \mathrm{~min}$. Finally, the template was removed via immersing the samples in toluene for $5 \mathrm{~min}$ in order to produce the structured thin films.

\section{f. Characterization}

FT-IR spectra were measured on a Bruker Alpha FT-IR spectrometer in transmission mode (layers on silicon wafers). All spectra were recorded in a range between 3600 and $500 \mathrm{~cm}^{-1}$ with 24 scans and a blank silicon wafer as background. UV-Vis absorption spectra were recorded on a Shimadzu spectrophotometer UV-1800 (300 to $1000 \mathrm{~nm}$ ).

The grazing incidence X-ray diffraction measurements were performed on a Rigaku SmartLab II X-ray diffractometer, which features the PhotonMax high-flux $9 \mathrm{~kW}$ rotating anode X-ray source, with a D/teX Ultra 250 detector. The measurements were performed in an incidence angle of $0.8^{\circ}$. The powder X-ray diffraction (XRD) measurements were taken on a RIGAKU Miniflex 600 with $\mathrm{D} /$ Tex Ultra detector using $\mathrm{CuK}_{\alpha}$ radiation $(\lambda=1.5418 \AA)$. The measurements were performed on a zerobackground sample holder. The diffraction patterns were evaluated with the SmartLabStudioII ${ }_{\mathrm{x} 64 \mathrm{v} 4.2 .890}$ software.

Scanning electron microscopic images were acquired on a TESCAN MIRA3 Field Emission Scanning Electron Microscope (FESEM) using an In-Beam secondary electron (SE) detector. The microscope was operated at $5 \mathrm{kV}$, with a working distance of about $4 \mathrm{~mm}$ and an electron beam spot size of $4 \mathrm{~nm}$. Samples for FESEM characterisations were coated with a $5 \mathrm{~nm}$ thin chromium layer by thermal evaporation. Energy Dispersive Spectroscopy (EDX) investigations were carried out with a Super Octane detector with a $60 \mathrm{~mm}^{2}$ active area (EDAX AMETEK, Mahwah, NJ, USA), using a working distance of $10 \mathrm{~mm}$ and an acceleration voltage of $15 \mathrm{kV}$.

Simultaneous GISAXS and GIWAXS measurements were performed at the Austrian SAXS Beamline $5.2 \mathrm{~L}$ of the electron storage ring ELETTRA (Italy). ${ }^{50}$ The setup had been adjusted to a $q$-range $(q=4 \pi / \lambda \sin (2 \theta / 2))$ between 0.1 and $2.4 \mathrm{~nm}^{-1}$ in in-plane and between 0.6 and $4.3 \mathrm{~nm}^{-1}$ in out-of-plane direction (GISAXS) as well as to resolve the angular range (2 $\theta)$ between 20.3 and $40.0^{\circ}$ in the GIWAXS characterizations. The measurements were performed at a photon energy of $8 \mathrm{keV}$. The samples were mounted on an Anton Paar DHS 1100 heating cell equipped with a specially designed dome having Kapton windows to provide high X-ray transmissivity and low background. The GIWAXS signal was monitored using a Dectris Pilatus 100k detector and the GISAXS signal with a Dectris Pilatus3 1M detector. The angular calibration of the detectors was carried out using $p$-bromo benzoic acid and silver behenate powder ( $d$-spacing of $58.38 \AA$ ), respectively. The sample chamber was purged with nitrogen during the whole experiment. The temperature range used was from 35 up to $400{ }^{\circ} \mathrm{C}$ with a heating rate of $10{ }^{\circ} \mathrm{C} \mathrm{min}^{-1}$. A temperature resolution of $1{ }^{\circ} \mathrm{C}$ could be obtained by having one frame every 6 seconds (5 seconds exposure). All measurements have been performed with a grazing angle of $0.23^{\circ}$. The off specular out-of-plane integration was done in a $q$-range between -0.06 to $0.03 \mathrm{~nm}^{-1}$ and the in-plane integration between $0.21-0.48 \mathrm{~nm}^{-1}$ (Fig. S3, ESI $\dagger$ ) with the data evaluation software SAXS DOG. ${ }^{51}$

\section{Conflicts of interest}

There are no conflicts to declare.

\section{Acknowledgements}

The authors gratefully acknowledge Graz University of Technology for financial support through the Lead Project Porous Materials at Work (LP-03). Moreover, the authors acknowledge the CERIC-ERIC consortium for the access to experimental facilities (Austrian SAXS beamline at Elettra Sincrotrone Trieste) and financial support. 


\section{References}

1 (a) P. Innocenzi and L. Malfatti, Chem. Soc. Rev., 2013, 42, 4198-4216; (b) P. Kumar, K.-H. Kim, K. Vellingiri, P. Samaddar, P. Kumar, A. Deep and N. Kumar, Biosens. Bioelectron., 2018, 104, 120-137; (c) L. Zhang, Z.-J. Zhao and J. Gong, Angew. Chem., Int. Ed., 2017, 56, 11326-11353.

2 Z. Wang, D. Cao, R. Xu, S. Qu, Z. Wang and Y. Lei, Nano Energy, 2016, 19, 328-362.

3 Y. Shi, Y. Wan and D. Zhao, Chem. Soc. Rev., 2011, 40, 3854-3878.

4 (a) S. Shen and Q. Wang, Chem. Mater., 2013, 25, 1166-1178; (b) C.-H. Lai, M.-Y. Lu and L.-J. Chen, J. Mater. Chem., 2012, 22, 19-30; (c) S. M. Gupta and M. Tripathi, High Energy Chem., 2012, 46, 1-9; (d) G. Wang, C. Li and H. Shan, ACS Catal., 2014, 4, 1139-1143.

5 S. Chandrasekaran, L. Yao, L. Deng, C. Bowen, Y. Zhang, S. Chen, Z. Lin, F. Peng and P. Zhang, Chem. Soc. Rev., 2019, 48, 4178-4280.

6 M.-H. Sun, S.-Z. Huang, L.-H. Chen, Y. Li, X.-Y. Yang, Z.-Y. Yuan and B.-L. Su, Chem. Soc. Rev., 2016, 45, 3479-3563.

7 A. Fischereder, M. L. Martinez-Ricci, A. Wolosiuk, W. Haas, F. Hofer, G. Trimmel and G. J. A. A. Soler-Illia, Chem. Mater., 2012, 24, 1837-1845.

8 Y. Türker and Ö. Dag, J. Mater. Chem., 2008, 18, 3467-3473.

9 H. Zhou, H. Xiong, R. Zhang, L. Zhang, L. Zhang, L. Li, W. Zhang, Z. Zhu and Z.-A. Qiao, Small, 2021, 17, 2100428.

10 Y. Guo, J. Tang, J. Henzie, B. Jiang, W. Xia, T. Chen, Y. Bando, Y.-M. Kang, M. S. A. Hossain, Y. Sugahara and Y. Yamauchi, ACS Nano, 2020, 14, 4141-4152.

11 B. T. Yonemoto, G. S. Hutchings and F. Jiao, J. Am. Chem. Soc., 2014, 136, 8895-8898.

12 T. Rath, C. Padeste, M. Vockenhuber, C. Fradler, M. Edler, A. Reichmann, I. Letofsky-Papst, F. Hofer, Y. Ekinci and T. Griesser, J. Mater. Chem. A, 2013, 1, 11135-11140.

13 (a) C. Buchmaier, M. Glänzer, A. Torvisco, P. Poelt, K. Wewerka, B. Kunert, K. Gatterer, G. Trimmel and T. Rath, J. Mater. Sci., 2017, 52, 10898-10914; (b) S. A. Alderhami, D. Collison, D. J. Lewis, P. D. McNaughter, P. O'Brien, B. F. Spencer, I. Vitorica-Yrezabal and G. Whitehead, Dalton Trans., 2019, 48, 15605-15612.

14 C. Buchmaier, T. Rath, F. Pirolt, A.-C. Knall, P. Kaschnitz, O. Glatter, K. Wewerka, F. Hofer, B. Kunert, K. Krenn and G. Trimmel, RSC Adv., 2016, 6, 106120-106129.

15 (a) B. Radha, S. Kiruthika and G. U. Kulkarni, J. Am. Chem. Soc., 2011, 133, 12706-12713; (b) L. Persano, A. Camposeo, F. Di Benedetto, R. Stabile, A. M. Laera, E. Piscopiello, L. Tapfer and D. Pisignano, Adv. Mater., 2012, 24, 5320-5326; (c) M. S. M. Saifullah, M. Asbahi, M. BintiKamran Kiyani, S. S. Liow, S. Bin Dolmanan, A. M. Yong, E. A. H. Ong, A. Ibn Saifullah, H. R. Tan, N. Dwivedi, T. Dutta, R. Ganesan, S. Valiyaveettil, K. S. L. Chong and S. Tripathy, ACS Appl. Mater. Interfaces, 2020, 12, 16772-16781; (d) J. Recatala-Gomez, H. K. Ng, P. Kumar, A. Suwardi, M. Zheng, M. Asbahi, S. Tripathy, I. Nandhakumar, M. S. M. Saifullah and K. Hippalgaonkar,
ACS Appl. Mater. Interfaces, 2020, 12, 33647-33655; (e) M. S. M. Saifullah, M. Asbahi, M. Binti-Kamran Kiyani, S. Tripathy, E. A. H. Ong, A. Ibn Saifullah, H. R. Tan, T. Dutta, R. Ganesan, S. Valiyaveettil and K. S. L. Chong, ACS Nano, 2017, 11, 9920-9929.

16 Y. Lu, J. Jia and G. Yi, CrystEngComm, 2012, 14, 3433-3440. 17 Y.-H. Hung, A.-Y. Lu, Y.-H. Chang, J.-K. Huang, J.-K. Chang, L.-J. Li and C.-Y. Su, ACS Appl. Mater. Interfaces, 2016, 8, 20993-21001.

18 R. van Dommelen, P. Fanzio and L. Sasso, Adv. Colloid Interface Sci., 2018, 251, 97-114.

19 H. W. Deckman and J. H. Dunsmuir, Appl. Phys. Lett., 1982, 41, 377-379.

20 (a) P. Labouchere, A. K. Chandiran, T. Moehl, H. Harms, S. Chavhan, R. Tena-Zaera, M. K. Nazeeruddin, M. Graetzel and N. Tetreault, Adv. Energy Mater., 2014, 4, 1400217; (b) S.-E. Cheon, H.-S. Lee, J. Choi, A. R. Jeong, T. S. Lee, D. S. Jeong, K.-S. Lee, W.-S. Lee, W. M. Kim, H. Lee and I. Kim, Sci. Rep., 2017, 7, 7336; (c) Y. G. Seo, K. Woo, J. Kim, H. Lee and W. Lee, Adv. Funct. Mater., 2011, 21, 3094-3103; (d) G. von Freymann, V. Kitaev, B. V. Lotsch and G. A. Ozin, Chem. Soc. Rev., 2013, 42, 2528-2554.

21 X. Ye and L. Qi, Nano Today, 2011, 6, 608-631.

22 (a) X. Chen, S. Yang, Y. C. Zheng, Y. Chen, Y. Hou, X. H. Yang and H. G. Yang, Adv. Sci., 2015, 2, 1500105; (b) L. Zhang, M. T. Hörantner, W. Zhang, Q. Yan and H. J. Snaith, Sol. Energy Mater. Sol. Cells, 2017, 160, 193-202. 23 M. T. Hörantner, W. Zhang, M. Saliba, K. Wojciechowski and H. J. Snaith, Energy Environ. Sci., 2015, 8, 2041-2047.

24 C. Geng, F. Li, Y. Fan, L. Zhang, S. Shi, Z.-H. Zhang, Y. Zhang, S. Xu and W. Bi, Cryst. Growth Des., 2018, 18, 5770-5779.

25 S. Amrehn, D. Berghoff, A. Nikitin, M. Reichelt, X. Wu, T. Meier and T. Wagner, Photonics Nanostructures - Fundam. Appl., 2016, 19, 55-63.

26 L. Galle, S. Ehrling, S. Lochmann, S. Kaskel, L. Bischoff and J. Grothe, ChemNanoMat, 2020, 6, 560-566.

27 (a) S. Schünemann, K. Chen, S. Brittman, E. Garnett and H. Tüysüz, ACS Appl. Mater. Interfaces, 2016, 8, 25489-25495; (b) F. Zhang, J. Song, M. Chen, J. Liu, Y. Hao, Y. Wang, J. Qu and P. Zeng, Phys. Chem. Chem. Phys., 2016, 18, 32903-32909.

28 Z. Yi, G. Niu, J. Luo, X. Kang, W. Yao, W. Zhang, Y. Yi, Y. Yi, X. Ye, T. Duan and Y. Tang, Sci. Rep., 2016, 6, 32314.

29 T. Fan, P. Sun, J. Zhao, Z. Cui and G. Cui, J. Electrochem. Soc., 2019, 166, D37-D43.

30 (a) R. Klenk, J. Klaer, R. Scheer, M. Lux-Steiner, I. Luck, N. Meyer and U. Rühle, Thin Solid Films, 2005, 480-481, 509-514; (b) W. Chen, J. Qi, C. Dong, J. Chen, Z. Shen, Y. He, S. Yang, T. Chen, C. Chen, Y. Li, M.-D. Li and M. Wang, ACS Appl. Energy Mater., 2019, 2, 5231-5242.

31 A. Fischereder, T. Rath, W. Haas, H. Amenitsch, D. Schenk, A. Zankel, R. Saf, F. Hofer and G. Trimmel, ACS Appl. Mater. Interfaces, 2012, 4, 382-390.

32 V. Perner, T. Rath, F. Pirolt, O. Glatter, K. Wewerka, I. Letofsky-Papst, P. Zach, M. Hobisch, B. Kunert and G. Trimmel, New J. Chem., 2019, 43, 356-363. 
33 T. Rath, M. Edler, W. Haas, A. Fischereder, S. Moscher, A. Schenk, R. Trattnig, M. Sezen, G. Mauthner, A. Pein, D. Meischler, K. Bartl, R. Saf, N. Bansal, S. A. Haque, F. Hofer, E. J. W. List and G. Trimmel, Adv. Energy Mater., 2011, 1, 1046-1050.

34 (a) H. Zhao, M. Zhou, L. Wen and Y. Lei, Nano Energy, 2015, 13, 790-813; (b) J. Weickert, R. B. Dunbar, H. C. Hesse, W. Wiedemann and L. Schmidt-Mende, Adv. Mater., 2011, 23, 1810-1828.

35 (a) J. Yu and C.-W. Kan, Fibers, 2018, 6, 70; (b) P. Liu, L. Bai, J. Yang, H. Gu, Q. Zhong, Z. Xie and Z. Gu, Nanoscale Adv., 2019, 1, 1672-1685.

36 (a) Y.-Y. Lin, Y.-J. Chen, F.-G. Tseng and D.-J. Yao, IEEE Nanotechnol. Mag., 2014, 8, 20-28; (b) J. A. Yabagi, M. I. Kimpa, M. N. Muhammad, N. Nayan, Z. Embong and M. Arif Agam, J. Sci. Technol., 2017, 9, 145-153; (c) A. Plettl, F. Enderle, M. Saitner, A. Manzke, C. Pfahler, S. Wiedemann and P. Ziemann, Adv. Funct. Mater., 2009, 19, 3279-3284.

37 S. Dunst, T. Rath, A. Radivo, E. Sovernigo, M. Tormen, H. Amenitsch, B. Marmiroli, B. Sartori, A. Reichmann, A.-C. Knall and G. Trimmel, ACS Appl. Mater. Interfaces, 2014, 6, 7633-7642.

38 E. Vakalopoulou, C. Buchmaier, A. Pein, R. Saf, R. C. Fischer, A. Torvisco, F. Warchomicka, T. Rath and G. Trimmel, Dalton Trans., 2020, 49, 14564-14575.

39 J. Fang, Y. Xuan and Q. Li, Sci. China: Technol. Sci., 2010, 53, 3088-3093.

40 T. Kuzuya, Y. Hamanaka, K. Itoh, T. Kino, K. Sumiyama, Y. Fukunaka and S. Hirai, J. Colloid Interface Sci., 2012, 388, 137-143.
41 (a) O. Glatter and O. Kratky, Small Angle X-Ray Scattering. Chapter 2 General Theory by Porod, Academic Press INC LTD., London, 1982; (b) H. M. A. Ehmann, O. Werzer, S. Pachmajer, T. Mohan, H. Amenitsch, R. Resel, A. Kornherr, K. Stana-Kleinschek, E. Kontturi and S. Spirk, ACS Macro Lett., 2015, 4, 713-716.

42 J. D. Peterson, S. Vyazovkin and C. A. Wight, Macromol. Chem. Phys., 2001, 202, 775-784.

43 J. E. Mark, The polymer data handbook, Oxford University Press, New York, Oxford, 2nd edn, 2009.

44 E. Vakalopoulou, T. Rath, M. Kräuter, A. Torvisco, R. C. Fischer, B. Kunert, R. Resel, H. Schröttner, A. M. Coclite, H. Amenitsch and G. Trimmel, ACS Appl. Nano Mater., 2022, 5, 1508-1520.

45 A. Aldiyarov, M. Aryutkina, A. Drobyshev, M. Kaikanov and V. Kurnosov, Low Temp. Phys., 2009, 35, 251-255.

46 D. G. Calatayud, T. Jardiel, M. Rodríguez, M. Peiteado, D. Fernández-Hevia and A. C. Caballero, Ceram. Int., 2013, 39, 1195-1202.

47 M. J. Turo and J. E. Macdonald, ACS Nano, 2014, 8, 10205-10213.

48 J. Choi, W. Choi and D. Y. Jeon, ACS Appl. Nano Mater., 2019, 2, 5504-5511.

49 J. Yu, Q. Yan and D. Shen, ACS Appl. Mater. Interfaces, 2010, 2, 1922-1926.

50 H. Amenitsch, M. Rappolt, M. Kriechbaum, H. Mio, P. Laggner and S. Bernstorff, J. Synchrotron Radiat., 1998, 5, 506-508.

51 M. Burian, C. Meisenbichler, D. Naumenko and H. Amenitsch, SAXSDOG: open software for real-time azimuthal integration of 2D scattering images. https://arxiv.org/abs/2007.02022v1. 